\title{
Synthesis and Characterization of Pure and Nano-Ag Impregnated Chitosan Beads and Determination of Catalytic Activities of Nano-Ag
}

\author{
Zahoor Ahmad ${ }^{1 *}$, Maryam Maqsood ${ }^{1}$, Mazher Mehmood ${ }^{2}$, Mirza Jameel Ahmad², \\ Muhammad Aziz Choudhary ${ }^{1}$ \\ ${ }^{1}$ Department of Chemistry, Mirpur University of Science and Technology (MUST), \\ Mirpur, (AJ\&K), Pakistan \\ ${ }^{2}$ Center of Nanotechnology, Department of Material and Metallurgy, \\ Pakistan Institute of Engineering and Applied Sciences (PIEAS), Islamabad, Pakistan
}

Received: $7^{\text {th }}$ December 2016; Revised: 19 ${ }^{\text {th }}$ December 2016; Accepted: 21 ${ }^{\text {st }}$ December 2016

\begin{abstract}
The synthesis of nano-Ag impregnated porous Chitosan beads, in crosslinked and uncrosslinked forms, was aimed to investigate their catalytic potential in reducing nitro group into amino by $\mathrm{NaBH}_{4}$. $\mathrm{The}$ material was found unique concerning the synthesis of well-defined Ag NPs and subsequently adsorbing them on its surface. The crosslinked and uncrosslinked chitosan beads were separately analyzed for the loading of $\mathrm{Ag}$ and its effect over the microstructures of the substrate. BET was used to explore the porous nature and pore size distributions of beads. At each stage, SEM coupled with EDX, FT-IR, and inductively coupled plasma (ICP) were employed to characterize the material. The catalytic activities of nano-Ag in crosslinked and uncrosslinked beads were determined by the reduction of 4Nitrophenol (4-NP) into 4-aminophenol (4-AP) by $\mathrm{NaBH}_{4}$; which is least effective for such reduction. The catalytic activities were monitored by UV-Vis spectrophotometer. The results demonstrated the nano-Ag as a reliable and active catalyst which made $\mathrm{NaBH}_{4}$ quite capable for the nitro reduction. Moreover, the catalytic activities of crosslinked chitosan substrate were found more reproducible as compared to the uncrosslinked substrate. Copyright (C) 2017 BCREC GROUP. All rights reserved
\end{abstract}

Keywords: Chitosan beads; Nano-Ag; Nitro reduction; $\mathrm{NaBH}_{4}$

How to Cite: Ahmad, Z., Maqsood, M., Mehmood, M., Ahmad, M.J., Choudhary, M.A. (2017). Synthesis and Characterization of Pure and Nano-Ag Impregnated Chitosan Beads and Determination of Catalytic Activities of Nano-Ag. Bulletin of Chemical Reaction Engineering \& Catalysis, 12 (1): 127-135 (doi:10.9767/bcrec.12.1.860.127-135)

Permalink/DOI: http://dx.doi.org/10.9767/bcrec.12.1.860.127-135

\section{Introduction}

Chitosan is a multifunctional polysaccharide constituted by $\beta(1-4), \quad 2$-amino-2-deoxy-Dglucan and 2-acetamidodeoxy-D-glucan [1]. The presence of amino and hydroxyl groups in each

* Corresponding Author.

E-mail: zahoorbuct@hotmail.com

Telp.: +925827961100 monomer make it diverse with reference to its reactivity and applications. It can strongly interact with different metals, dyes, drugs and enzymes for their detection, degradation, controlled delivery and enhancing reactions, respectively [2]. It can be modified into different morphologies like powder, gels, beads, membranes, and fibers [3]. The chitosan beads of different dimensions always remained central for drug delivery, enzyme immobilization, cell 
culturing, chromatographic support, and adsorption of metal ions [2]. Due to having $\mathrm{N}$ and $\mathrm{O}$ as structural and binding elements, it can also hold and anchor different metal nanoparticles. The nano-Ag was preferably anchored due to its unique optical, conductive [4,5], and biomedical properties [6-8]. The nano-Ag can also demonstrate reliable oxidative and reductive catalytic properties $[9,10]$.

There are many reports, where various supports based nano-Ag have been explored as catalyst for the reduction of nitro group using $\mathrm{NaBH}_{4}$ [11-13]. There are also some reports, where reflux temperature was used for the synthesis of nano-Ag mediated by Chitosan [14, 15]. However, the designing of nano-Ag, mediated by chitosan beads at room temperature and the analysis of its catalytic reduction under mild conditions was investigated first time by our group. Herein, the fabrication of porous crosslinked and uncrosslinked chitosan beads and in situ adsorption of nano-Ag was performed. The internal crosslinking was aimed to limit its structural deformation and achieve uniform distribution of nano catalyst. The as designed material was characterized by FT-IR, SEM, and ICP. The pore size and surface area was studied by BET. The catalyst distribution, efficiency and microscopic bead deformation in crosslinked and uncrosslinked form was comparatively investigated. The catalytic potentials of nano-Ag to reduce $4-\mathrm{NP}$ by $\mathrm{NaBH}_{4}$ into 4-AP under mild conditions were studied and effect of bead type on catalytic reproducibility was evaluated.

\section{Materials and Methods}

\subsection{Materials}

Chitosan (extracted from crab shells), Epichlorohydrin ( $\geq 98 \%$, density $\left.1.180 \mathrm{~g} / \mathrm{cm}^{3}\right)$ supplied by Fluka, $\mathrm{HCl}, \mathrm{NaOH}$ and acetic acid (purchased from Merck), $\mathrm{AgNO}_{3}$ (Fischer suppliers) and deionized water.

\subsection{Experimentals}

The complete experimental procedure is divided into following main steps.

Conversion of Chitin into Chitosan: It was extracted from crab shells in the form of chitin collected from coastal areas of Pakistan (Karachi fisher's industry). Chitin was converted into chitosan using standard methods involving demineralization, deproteinization and deacetylation as reported by Al Sagheer and others [16-18].
Fabrication of Chitosan beads and loading nano Ag: Fabrication of chitosan beads was achieved by taking $6 \mathrm{~g}$ of chitosan flakes, which were dissolved in $90 \mathrm{~mL}$ of $5 \% \mathrm{v} / \mathrm{v}$ acetic acid solution under continuous stirring for about 24 $\mathrm{hrs}$ at room temperature. It was divided into four beakers and each one contained $20 \mathrm{~mL}$. These were named as $\mathrm{A}, \mathrm{B}, \mathrm{C}$ and $\mathrm{D}$, respectively. The $1 \%, 5 \mathrm{~mL}$ epichlorohydrin, was added in beakers named as A and B to develop cross linking within dissolved chitosan and beakers named as C and D were treated without a cross linking agent. The as prepared solutions were separately added drop wise into 100 $\mathrm{mL}$ of $2 \mathrm{M}, \mathrm{NaOH}$ casting solution, which due to insolublization converted into beads. The beads were kept in the solution of $\mathrm{NaOH}$ for 24 hours, and were filtered, washed several times with distilled water and dried for further process and characterization as well.

Moreover, 30 beads from beaker B and D were immersed into $100 \mathrm{~mL}$ of $10 \mathrm{mM} \mathrm{AgNO}_{3}$ solution. Where chitosan reduced $\mathrm{Ag}^{+}$into $\mathrm{Ag}$ and then transformed it into nanoparticles which remained impregnated at the surface of beads. These beads were filtered and rinsed with deionized water after $68 \mathrm{~h}$. Due to loading of Ag NPs, these turned into black color. These were again separately saved as B and D which were loaded with $\mathrm{Ag}$ and designated as $\mathrm{Ag}$ loaded cross linked and uncross linked chitosan beads. The types of all beads are given in Table 1 .

Catalysis: The catalytic potential of nano-Ag was analyzed in crosslinked (B) and uncrosslinked beads (D) and without nano-Ag crosslinked (A) and uncrosslinked (C) were taken as reference. The experimental procedure was designed as: 3 beads from each sample i.e. sample A, B C and D were separately dipped into $5 \mathrm{~mL}$ of $0.05 \mathrm{mM} 4$-NP solution. It was allowed to soak 4-NP for 24 hours and their UV-vis spectrum was recorded to confirm the adsorption of substrate. In each sample, 5 $\mathrm{mM}, 5 \mathrm{~mL} \mathrm{NaBH} 4$ solution was added, respectively. It was thoroughly shacked and its reducing activity in each sample was monitored by UV-vis spectrophotomer. The samples (B \& D) where nano-Ag was present has demonstrated pronounced catalytic effect as compared to reference samples (C \& D) which were without nano-Ag, where reduction of Nitro into amino purely by $\mathrm{NaBH}_{4}$ is negligible.

\subsection{Characterization Techniques}

Surface morphology of dried beads and their 
EDX was carried out using FEI Nova SEM 430. Further Ag quantification was carried out by ARL-3400 model ICP-AES. The structural analysis of porous chitosan beads was carried out using FTIR spectrophotometer (NICOLET 6700-FTIR). The spectra were recorded in transmittance mode, scanning from 4000-400 $\mathrm{cm}^{-1}$ with resolution of $6 \mathrm{~cm}^{-1}$. The surface area, pore size distribution of as synthesized beads was measured by BET using ASAP 2020 Micromeritics BET analyzer under liquid $\mathrm{N}_{2}$.

\section{Results and Discussion}

The as synthesized crosslinked and uncrosslinked material was observed under SEM, which are shown in Figures 1 and 2, with their EDX data, respectively. According to Figure 1, the whole sectional and magnified view of sample A, which are shown as $\mathrm{A}(\mathrm{I})$ and $\mathrm{A}(\mathrm{II})$, reflected the fibrous network of natural polymer. All fibers of polymers are quite even and smooth with having intermingling. The SEM displayed the fibrous detail of crosslinked chi-

Table 1. The table is showing types of samples beads with different names.

\begin{tabular}{ccc}
\hline Beads & Crosslinked/Uncross linked & Ag loaded/not loaded \\
\hline A & Crosslinked beads & Not Ag loaded \\
B & Crosslinked beads & Ag loaded \\
C & Uncrosslinked beads & Not Ag loaded \\
D & Uncrosslinked beads & Ag loaded \\
\hline
\end{tabular}
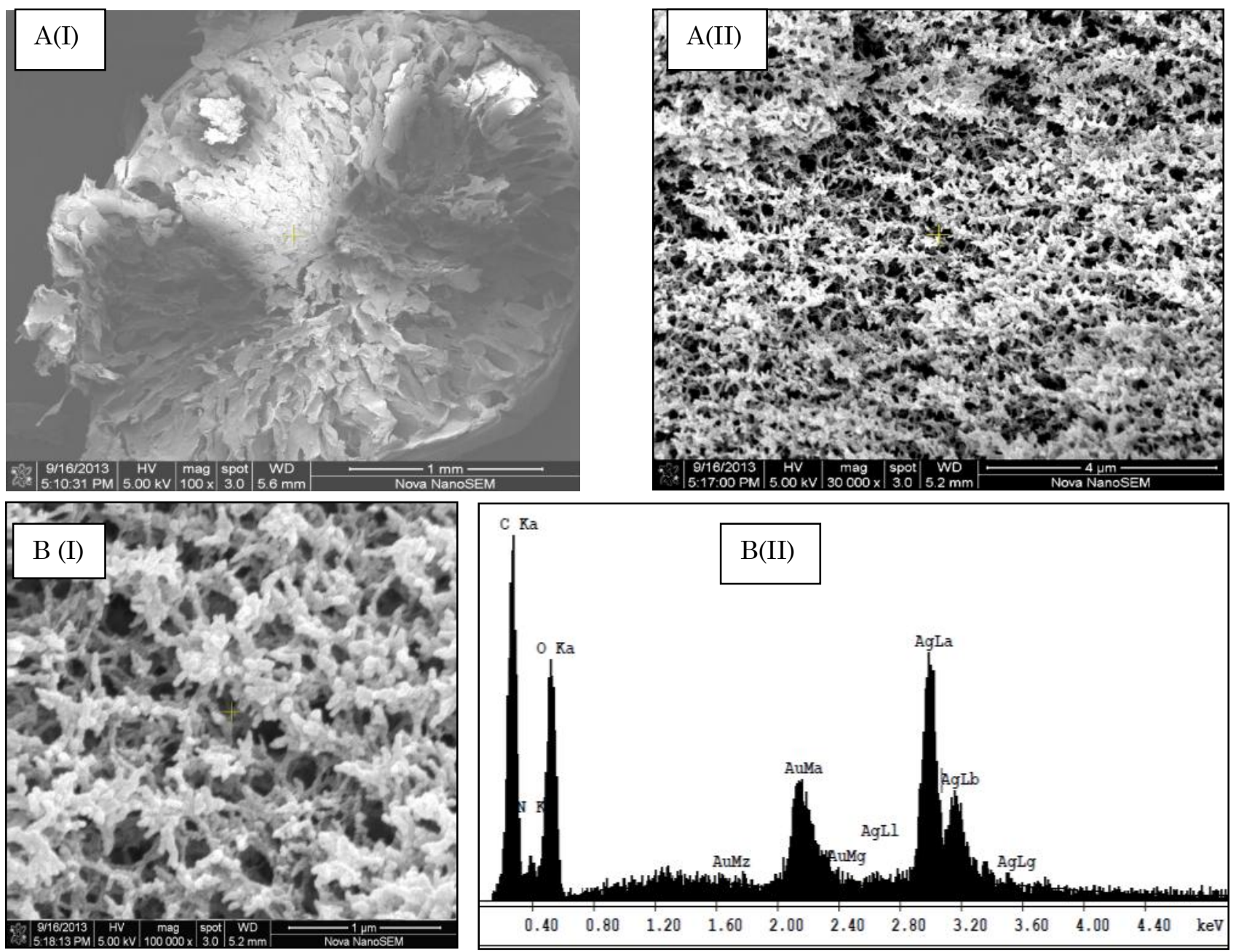

Figure 1. SEM picture of cross sectional and magnified view of crosslinked sample A are shown as A(I) and (II), the Ag loaded over cross linked chitosan beads having EDX data are displayed in B(I) and (II), respectively 
tosan beads with reticulate appearance. The sample B which is reflected in Figure B(I) expressed the similar reticulate network loaded by small particles of nano-Ag. Due to being the nanoparticles over these fibers the surface could not remain even and smooth as it was displayed by sample A. However, the reticulate texture seemed to remain intact. Therefore, it was believed that the presence of crosslinker, polymer sustainability, i.e. mechanical strength, remained preserved. The crosslinker proved helpful to avoid the rupture within texture even after loading nanoparticles.

The proof of particle being a Ag material, EDX analysis was taken which is unveiled in Figure B(II) and Table 2. The presence of C, N, and $\mathrm{O}$ is mainly related with polymer constituents and $\mathrm{Ag}$ which is $17 \%$ is due to the nanoparticles on the surface of fibrous network. Moreover, Figure 2 has been used to find

Table 2. Showing data of EDX plot of sample B

\begin{tabular}{ccc}
\hline Element & Weight, \% & Atomic, $\%$ \\
\hline C K & 35.67 & 52.61 \\
N K & 8.98 & 11.35 \\
O K & 29.27 & 32.41 \\
Ag L & 17.35 & 2.85 \\
\hline
\end{tabular}
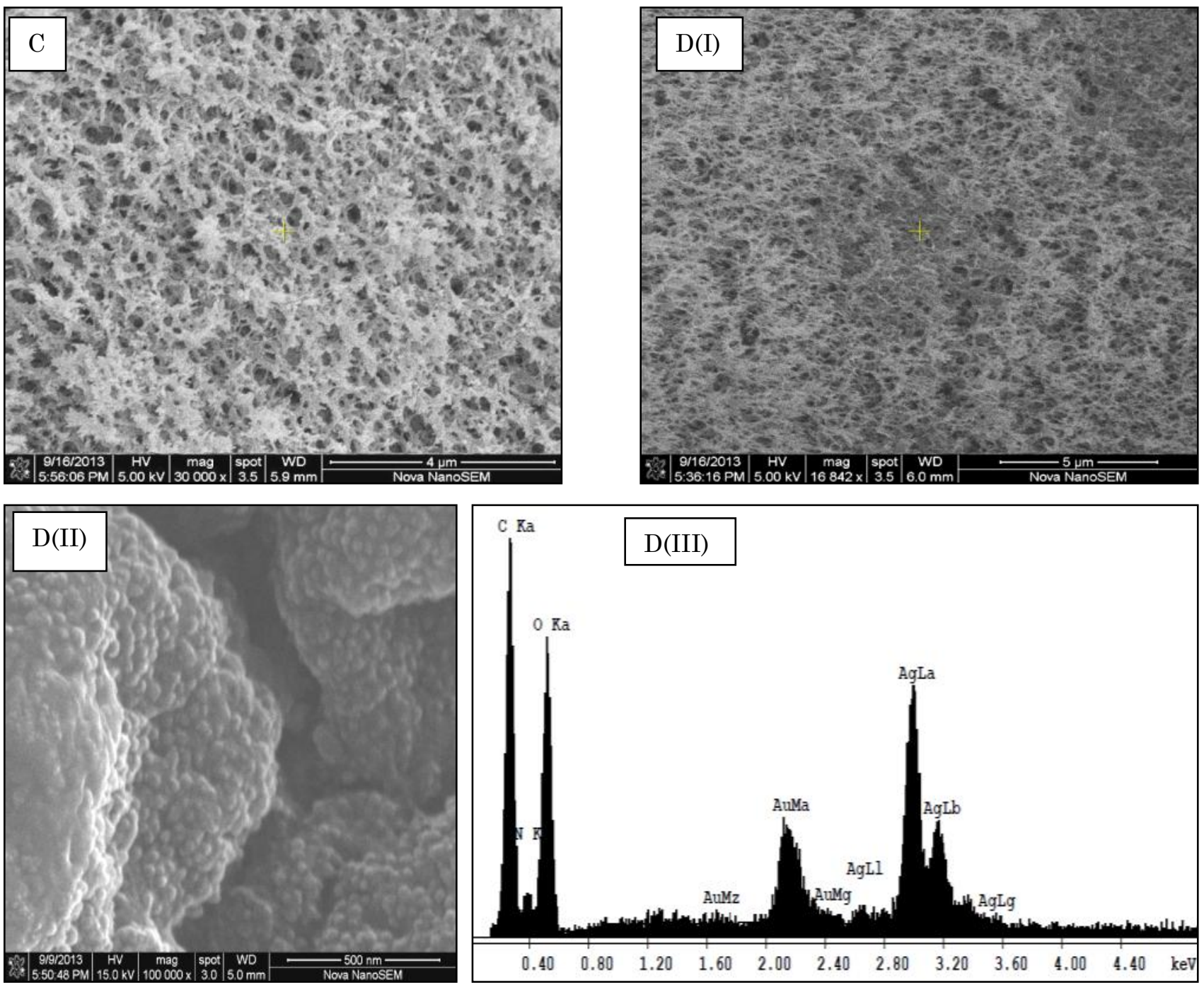

Figure 2. SEM pictures of uncrosslinked beads, Ag loaded beads, broken portion of bead fibers, and EDX plot are displayed as C, D (I), D(II) and D(III), respectively. 
the morphological details of uncrosslinked sample C. According to Figure 2C, although the texture appearance is fibrous and reticulated, but it is quite thin due to missing of covalent crosslinking. However, when it was loaded with nano-Ag, it developed strain and then it cracked from some regions and thus could not remain uniform throughout as expressed by Figure 2D (I, II). Due to lack of internal binding the mechanical strength could not be retained and texture rupture was clearly seen as demonstrated in Figure 2D(II). By comparison, the crosslinked beads have shown retainability in their texture after loading Ag as compared to uncrosslinked beads. Therefore, it can be inferred that crosslinked beads have more potential to remain uniform after adsorbing the catalyst and catalyst distribution was also quite uniform. The Ag analysis was achieved by EDX and it is shown in Figure D(III) and its data is tabulated in Table 3.

According to the EDX details the concentration of $\mathrm{Ag}$ under same molar conditions increased to $20 \%$ as compared to the crosslinked beads. So that it was concluded that thinner fiber which belonged to uncrosslinked beads have used more surface area to reduce and adsorb Ag, which in return ruptured the texture of their beads.

Additionally ICP-AES was used to quantify $\mathrm{Ag}$ in nano-Ag impregnated chitosan beads (B\&D) under acid digestion, and it is reflected in Table 4. The $\mathrm{Ag}^{+}$percentage in sample $\mathrm{B}$ and $\mathrm{D}$ was calculated relative to their masses. The results showed high $\mathrm{Ag}^{+}$content in the sample $D$ (uncrosslinked beads) as compared to the sample B (crosslinked beads). The results are supporting the EDX data. The less concentration of Ag as ICP-AES reflected compared to EDX may be due to incomplete acid digestion.

Overall, the FT-IR of crosslinked and uncrosslinked chitosan beads, and their respective
nano-Ag loaded forms are shown in Figures 3(a) and (b). Their peaks trend and position seemed to be quite comparable. The FT-IR bands, which have been shown in Figure 3(a) of pure chitosan beads of crosslinked (A) and uncrosslinked (C), respectively are almost comparable. The bands appearing at 3298,2867 , and $1417 \mathrm{~cm}^{-1}$ are related with $(\mathrm{N}-\mathrm{H}, \mathrm{O}-\mathrm{H}), \mathrm{C}-\mathrm{H}$ and $\mathrm{C}-\mathrm{N}$ stretching $[19,21]$, the vibration at $1580 \mathrm{~cm}^{-1}$ is related with $\mathrm{N}-\mathrm{H}$ bending [13], $\mathrm{C}-\mathrm{O}-\mathrm{C}$ asymmetric stretching appeared at $1014 \mathrm{~cm}^{-1}$, which is for glycosidic linkage [21,22].

Similarly, Ag loaded crosslinked (B) and uncrosslinked (D) chitosan beads are reflected in Figure 3(b). According to the data, the stretching vibration $(\mathrm{N}-\mathrm{H}, \mathrm{O}-\mathrm{H}), \mathrm{C}-\mathrm{H}$ and $\mathrm{C}-\mathrm{N}$ appeared at 3242,2860 , and $1304 \mathrm{~cm}^{-1}$, respectively. The $\mathrm{N}-\mathrm{H}$ bending vibration has been observed at $1566 \mathrm{~cm}^{-1}$ and glycocidic $\mathrm{C}-\mathrm{O}-\mathrm{C}$ asymmetrical stretching appeared at $986 \mathrm{~cm}^{-1}$. The bands related with $\mathrm{C}-\mathrm{N}, \mathrm{C}-\mathrm{O}-\mathrm{C}$ have been shifted toward the lower energy due to physical interaction with nano $\mathrm{Ag}$ [23]. Moreover, such an interaction was also depicted by peak at 809 $\mathrm{cm}^{-1}$, which is related to nano $\mathrm{Ag}-\mathrm{O}$ [24].

\subsection{BET analysis}

In order to analyze the pore size and its surface area, the Brunauer, Emmett and Teller (BET) analysis was carried out using ASAP 2020 Micromeritics BET analyzer. $\mathrm{N}_{2}$ gas was used as adsorbate at $77 \mathrm{~K}$ and pure chitosan beads and metal adsorbed porous chitosan beads were assayed as adsorbent. The linear isotherm plots for these samples that relate the extent of adsorbate being adsorbed on the surface of each sample to relative pressure were drawn as shown in Figure 4 a and b. These results were then used to quantify BET surface areas. The corresponding values for each sample are presented in Table 5.

Table 3. Showing data of EDX of sample D

\begin{tabular}{ccc}
\hline Element & Weight, \% & Atomic, \% \\
\hline $\mathrm{C} \mathrm{k}$ & 32.89 & 50.63 \\
$\mathrm{~N} \mathrm{k}$ & 8.26 & 10.90 \\
$\mathrm{O} \mathrm{K}$ & 29.55 & 34.16 \\
$\mathrm{Ag} \mathrm{L}$ & 20.08 & 3.44 \\
\hline
\end{tabular}

Table 4. ICP-AES results for silver in chitosan beads

\begin{tabular}{cc}
\hline Element (Silver) & \% Concentration \\
\hline Sample B & 13.924 \\
Sample D & 15.864 \\
\hline
\end{tabular}


The BET is the most common method which is used to describe specific surface area. The mathematical equation, $1 / W\left[\left(P^{o} / P\right)-1\right]$ $=1 / W_{m} C+\left((C-1) / W_{m} C\right)\left(P / P^{\circ}\right), \quad$ is followed for linear plot between $1 / W\left[\left(P / P_{\circ}\right)-1\right]$ and $P / P_{\text {。 }}$. In this equation, $W$ denotes the quantity of adsorbed gas, $P / P_{0}$ stands for relative pressure, $W_{m}$ is the volume of adsorbed mono layer and $C$ is a constant. Moreover, the surface area was

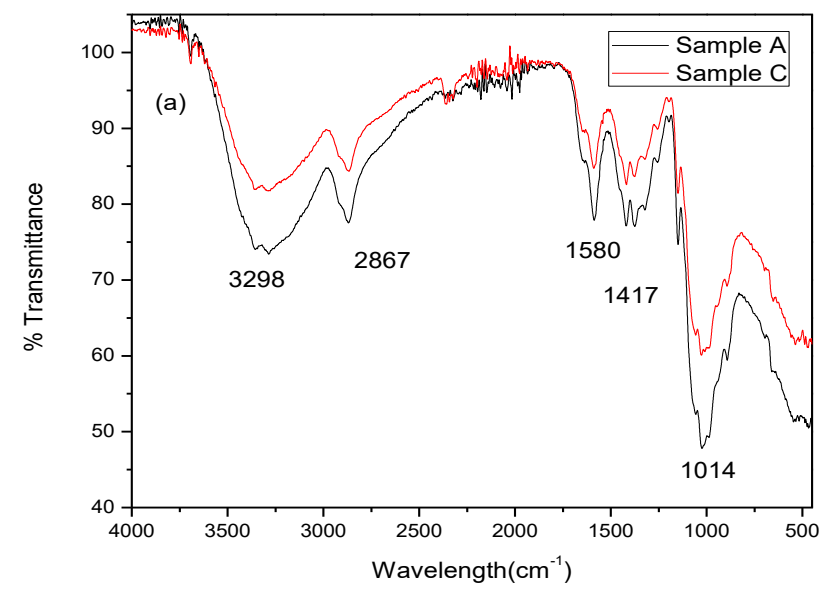

a) calculated using the relation: $S_{t}=W_{m} N A_{c s} / M$, where $N$ is Avogadro's number, $M$ is molecular weight of adsorbate and $A_{c s}$ adsorbate cross sectional area which is $16.023 \times 10^{23}$ for $\mathrm{N}_{2}$.

From the BET results, it is clear that among bead samples which are without silver, i.e. the surface area of crosslinked sample (A) is more as compared to uncrosslinked (C). However, the sample B displayed less surface

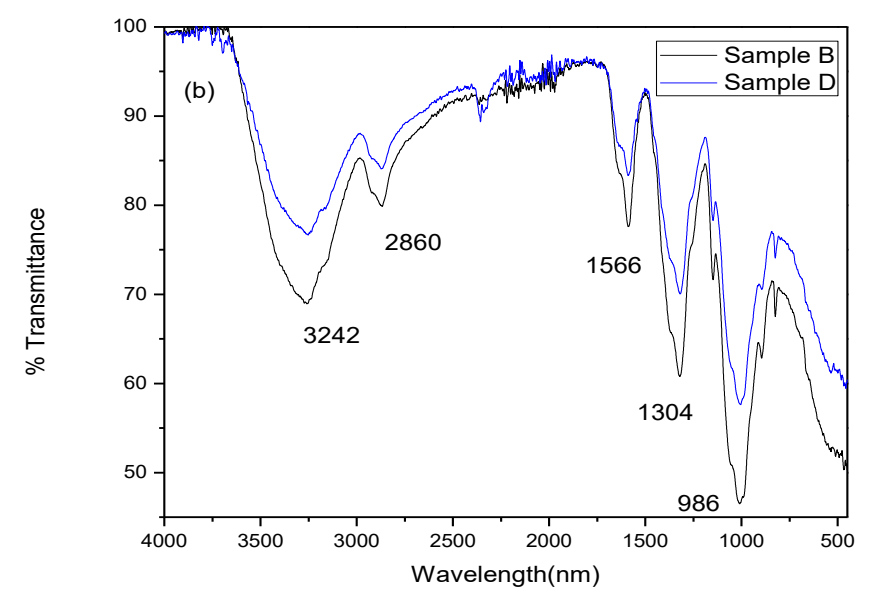

b)

Figure 3. a) FT-IR spectra of chitosan beads of A and C samples; b) FT-IR spectra of silver adsorbed samples, which are B and D
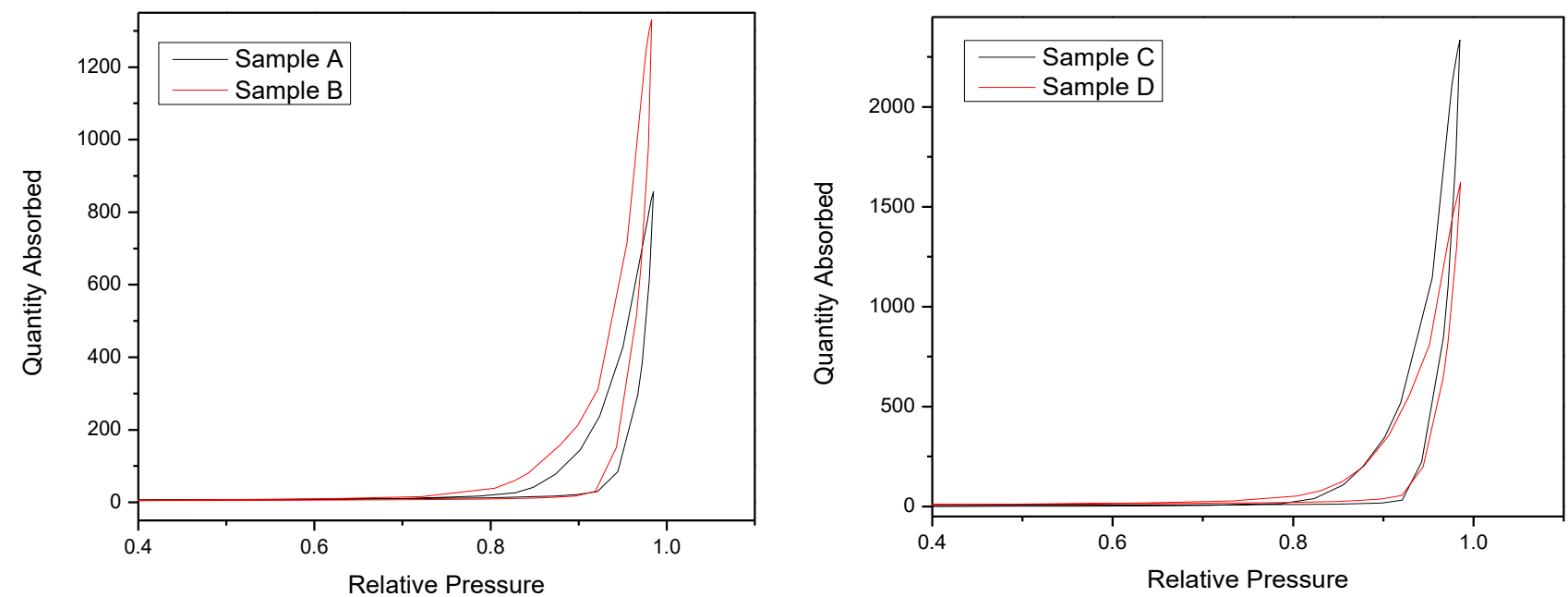

Figure 4. BET isotherms of crosslinked, Ag loaded crosslinked, uncrosslinked and Ag loaded uncrosslinked chitosan beads.

Table 5. Surface area results for synthesized beads

\begin{tabular}{cccc}
\hline No. & Samples & BET Surface area $\left(\mathrm{m}^{2} \mathrm{~g}^{-1}\right)$ & BJH adsorption pore width $\left(\mathrm{A}^{\circ}\right)$ \\
\hline 1 & Sample A & 19.348 & 610.6 \\
2 & Sample B & 13.326 & 548.5 \\
3 & Sample C & 17.326 & 572.4 \\
4 & Sample D & 30.250 & 564.3 \\
\hline
\end{tabular}


area as compared to $\mathrm{C}$ due to loading of Ag. The surface area of sample D was found unusual due to ruptures developed within pores and thus surface area deemed to be increased significantly. Similarly the pore size of $\mathrm{A}$ is less as compared to $\mathrm{C}$, and same trend was seen for their nano-Ag loaded forms. According to the classification of International Union of Pure and Applied Chemistry (IUPAC), the pores can be divided according to their diameter $(d)$ into macrospores $(d>50 \mathrm{~nm})$, mesopores $(2<d<50$ $\mathrm{nm}$ ) and micropores $(d<2 \mathrm{~nm})$. The BJH results show that as synthesized chitosan beads possessed macropores as their diameter is more than $50 \mathrm{~nm}$. The BET and SEM supported that crosslinked beads expressed more uniform and controlled trend in their morphology, pore size and surface area as compared to their uncrosslinked forms.

\subsection{Catalytic activities of Nano-Ag}

Reduction of nitro group remained serious challenge, where $\mathrm{NaBH}_{4}$ was seen as the least
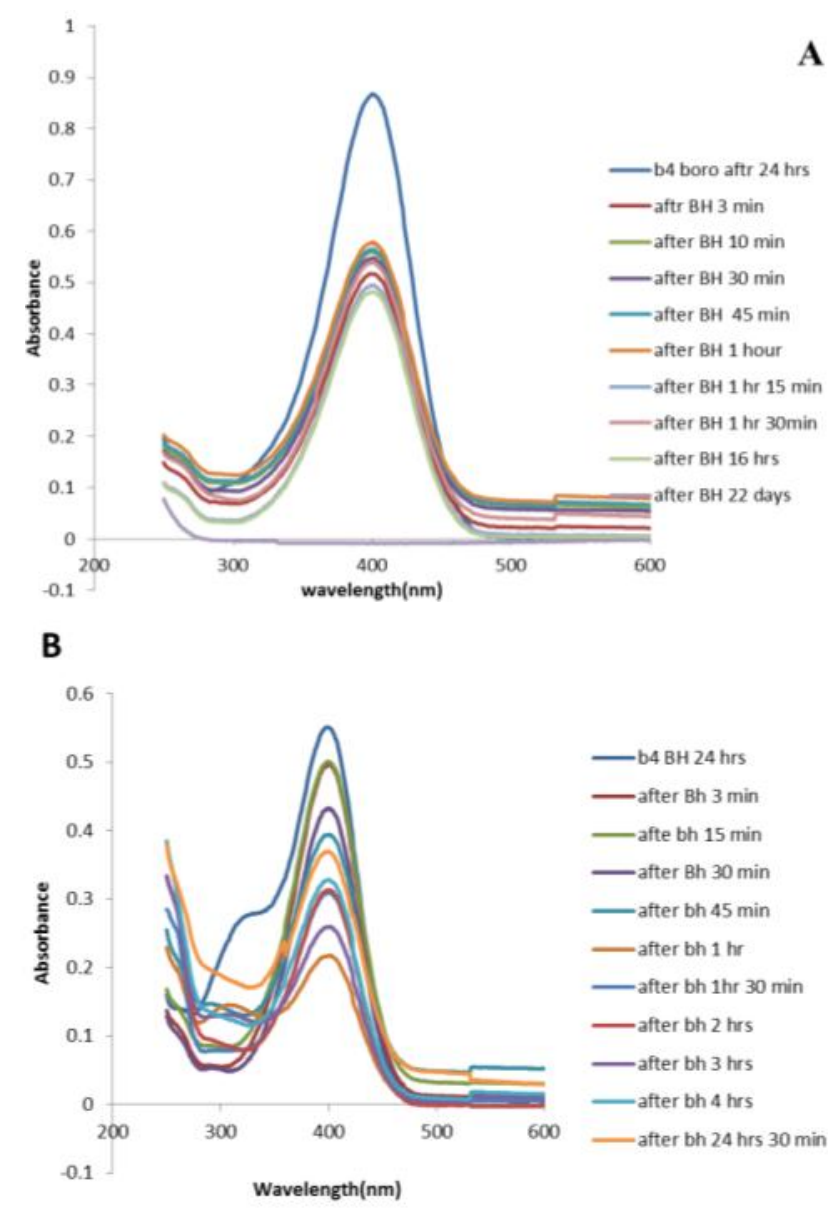

effective and others metal systems including $\mathrm{Sn} / \mathrm{HCl}$ are not reliable too due to nonselectivity $[25,26]$. As the nano regime is capable to be more effective, selective, and has larger turnover capacity, therefore, herein nano$\mathrm{Ag}$ was investigated as catalyst for reduction of 4-NP into 4-AP with $\mathrm{NaBH}_{4}$. Similar studies have been investigated using nano-Ag with different supports [27,28], but in situ synthesis of nano-Ag by chitosan under mild conditions, and later on acting as a catalyst is performed here. The effect of support being crosslinked and uncrosslinked was also analyzed. The experiment was designed where the reduction of 4-NP into 4-AP was carried out in all samples, i.e. A, B, C, and D. The catalytic reproducibility of nano-Ag is compared for crosslinked (B) and uncrossllinked (D) supports. The samples A and $\mathrm{C}$ were taken as reference.

The results are also correlated with pore size and surface area measured by BET analysis. The whole catalytic spectrum is shown in Figure 5. According to Figure 5(A) and (C), the reduction of 4-Nitrophenol by $\mathrm{NaBH}_{4}$ into 4-

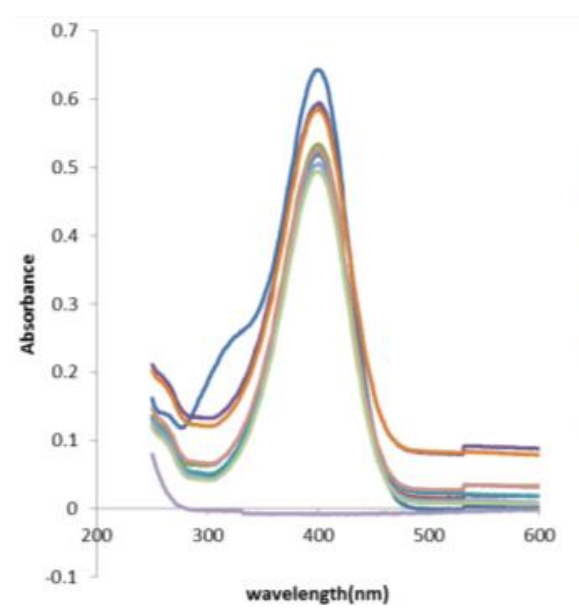

C

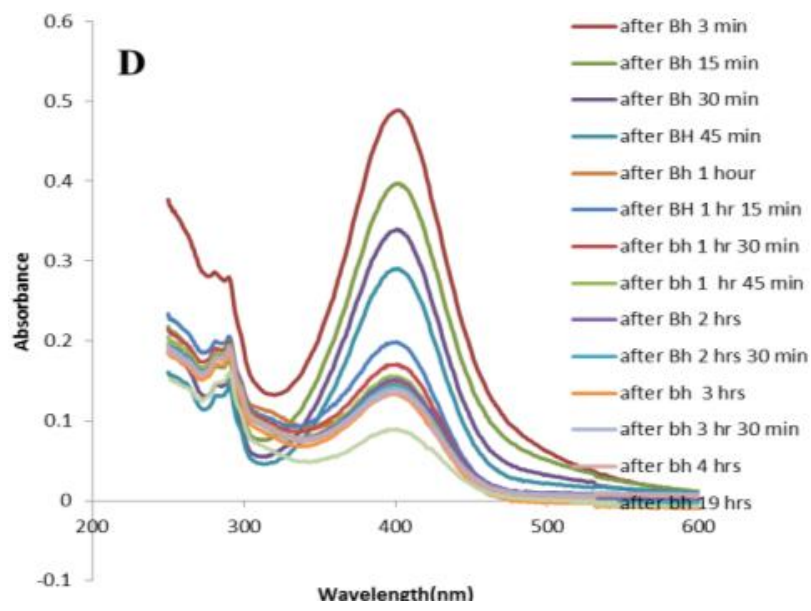

Figure 5. Catalytic activities of Ag nanoparticles are shown comparatively with controlled beads having no nano Ag. The reference samples are shown in Figures A and C, while role of Ag is shown in Figures B and D, respectively 
aminophenol was found to be quite low, which validated that $\mathrm{NaBH}_{4}$ is least effective for the reduction of Nitro group as it is reported elsewhere $[17,18]$. The absorption of $4-\mathrm{NP}$ is at 400 $\mathrm{nm}$ which is quite overlapping and even after $16 \mathrm{hrs}$, there is $3-4 \%$ conversion in 4 -AP. However, when similar reaction was carried out in nano-Ag impregnated chitosan beads, the significant catalytic effect was observed. According to the data shown in Figure 5(B), the maximum of 4-NP has been converted into its 4-AP within 3-4 hours. It was clearly reflected that initial absorption, i.e. $0.6 \mathrm{au}$, was reduced to less than $0.2 \mathrm{au}$, which is $80 \%$ conversion of 4 $\mathrm{NP}$ into 4AP. The same pattern of reduction was shown by sample D as shown by Figure 5(D). Moreover, it has been revealed by comparing the Figure 5(B) and (D), that reliable reproducibility is demonstrated by crosslinked chitosan support as compared to uncrosslinked support. Furthermore, the soaking of 4-NP in pure chitosan beads was also observed, which was more as compared to nano-Ag loaded chitosan beads. This behavior might be due to the more degree of chitosan functionalities available in pure form as compared to nano- $\mathrm{Ag}$ loaded form.

\section{Conclusions}

It has been found that chitosan beads are successful potential materials to synthesize and anchor the Ag nanoparticles at room temperature. The loading of $\mathrm{Ag}$ nanoparticles is uniform at the crosslinked chitosan beads as compared to uncrosslinked chitosan beads. It can cause structural microscopic distortion in the uncrosslinked form. The anchored $\mathrm{Ag}$ nanoparticles remained separated over as synthesized beads and thus demonstrated the catalytic reduction of 4-NP with $\mathrm{NaBH}_{4}$. The catalyst proved efficient which enabled the reagent to reduce nitro group that was believed to be least effective for the reduction of nitro group. The study is also an important guide to load nano-Ag over different polymers supports and analyze its catalytic behavior.

\section{Acknowledgement}

Higher Education Commission (HEC), Pakistan is gratefully acknowledged for financial assistance to complete the work. Thankful to Dr. Tashfeen Akhtar, Dept. of Chemistry, MUST, for proof reading and syntax corrections.

\section{References}

[1] Senay, A., Çetinus, H., Nursevin Ö. (2003). Immobilization of Catalase into Chemically Crosslinked Chitosan Beads. Enzyme and Microbial Technology, 32: 889-894.

[2] Ming-Shen, C., Pang-Yen, H., Hsing-Ya, L., (2004). Adsorption of Anionic Dyes in Acid Solutions Using Chemically Cross-Linked Chitosan Beads. Dyes and Pigments, 60: 6984.

[3] El-hefian, E.A., Nasef, M.M., Yahaya, A.H. (2011). Chitosan Physical Forms: A Short Review. Australian Journal of Basic and Applied Science, 5: 670-677.

[4] Jin, R., Cao, Y.C., Hao, E., Métraux, G.S., Schatz, G.C., Mirkin, C.A. (2003). Controlling Anisotropic Nanoparticle Growth through Plasmon Excitation. Nature, 425: 487-490.

[5] Debarre, A., Jaffiol, R., Julien, C., Tchenio, P., Mostafavi, M. (2004). Scattering from Single Ag Aggregates in Presence of EDTA. Chemical Physics Letters, 386: 244-247.

[6] Xu, X., Yang, Q., Wang, Y., Yu, H., Chen, X., Jing, X. (2006). Biodegradable Electrospun Poly(L-Lactide) Fibers Containing Antibacterial Silver Nanoparticles. European Polymer Journal, 42: 2081-2087.

[7] Liu, I., Sonshine, D.A., Shervani, S., Hurt, R.H. (2010). Controlled Release of Biologically Active Silver from Nanosilver Surfaces. ACS Nano, 4: 6903-6913.

[8] Krishna, R.K.S.V., Ramasubba, R.P., Lee, Y.I., Kim, C. (2012). Synthesis and Characterization of Chitosan-PEG-Ag Nano Composites for Antimicrobial Application, Carbohydrate Polymers, 87: 920-925.

[9] Tsujino, K., Matsumura, M. (2005). Boring Deep Cylindrical Nanoholes in Silicon Using Silver Nanoparticles as a Catalyst. Advanced Materials, 17: 1045-1047.

[10] Shimizu, K., Miyamoto, Y., Satsuma, A. (2010). Silica-Supported Silver Nanoparticles with Surface Oxygen Species as a Reusable Catalyst for Alkylation of Arenes. Chem. Cat. Chem, 2: 84-91.

[11] Kunio, E., Ryoko, I., Tomokazu, Y. (2004). Preparation of PAMAM- and PPI-Metal (Silver, Platinum, and Palladium) Nanocomposites and their Catalytic Activities for Reduction of 4-Nitrophenol. Langmuir, 20: 237 243.

[12] Subhra, J., Sujit, K.G., Sudip, N., Surojit, P., Snigdhamayee, P., Sudipa, P., Soumen, B., Takeshi, E., Tarasankar, P. (2006). Synthesis of Silver Nanoshell-Coated Cationic Polysty- 
rene Beads: A Solid Phase Catalyst for the Reduction of 4-Nitrophenol. Applied Catalysis A: General, 313: 41-48.

[13] Annamalai, L., Thumu, U.B.R., Thalappil, P. (2011). Supported Quantum Clusters of Silver as Enhanced Catalysts for Reduction. Nanoscale Research Letters, 6(123): 1-9. doi: 10.1186/1556-276X-6-123

[14] Dongwei, W., Wuyong S., Weiping, Q., Yongzhong, Y., Xiaoyuan, M. (2009). The Synthesis of Chitosan-Based Silver Nanoparticles and their Antibacterial Activity. Carbohydrate Research, 344: 2375-2382.

[15] Dongwei, W., Weiping, Q. (2008). Facile Synthesis of $\mathrm{Ag}$ and $\mathrm{Au}$ Nanoparticles Utilizing Chitosan as a Mediator Agent. Colloids and Surfaces B: Biointerfaces, 62: 136-142.

[16] Al Sagheer, F.A., Al-Sughayer, M.A., Muslim, S., Elsabee, M.Z. (2009). Extraction and Characterization of Chitin and Chitosan from Marine Sources in Arabian Gulf. Carbohydrate Polymers, 77: 410-419.

[17] Rudrapatnam, N., Kittur,T., Kittur, F.S. (2002). Chitin - The Undisputed Biomolecule of Great Potential, Critical Reviews in Food Sciences and Nutrition. 43(1): 61-87.

[18] Kubota, N. (1997). Permeability Properties of Chitosan-Transition Metal Complex Membranes. Journal of Applied Polymer Science, 64: 819-822.

[19] Zahoor, A., Teng, Q., Wang, H., Choudhry, M. A., Li, X. (2011). Synthesis and Characterization of Ag@polycarbazole Coaxial Nanocables and their Enhanced Dispersion Behavior. Metals and Materials International, 17: 417423.

[20] Zahoor, A., Teng, Q., Zhang, J., Li, X. (2009). Synthesis and Characterization of Ag@Polycarbazole Nanoparticles and their Novel Optical Behavior. Journal of Materials Science, 44: 6054-6059.

[21] Duan, H., Teng, Q.,H. Guo, H., Ye, J., Yuan, Y., Li, X. (2016). The Aminolysis of StyreneMaleic Anhydride Copolymers for a New Modifier Used in Urea-Formaldehyde Resins. International Journal of Adhesion and Adhesives, 66: 138-146.
[22] Iuliana, S., Teaca, C-A., Ruxanda, B. (2011). Preparation and Characterization of Adipic Acid-Modified Starch Microparticles/Plasticized Starch Composite Films Reinforced by Lignin. Journal of Materials Science, 46: 3241-3251.

[23] Govindan, S., Nivethaa, E.A.K., Saravanan, R., Narayanan, V., Stephen, A. (2012). Synthesis and Characterization of ChitosanSilver Nanocomposite. Applied Nanoscience, 2: 299-303.

[24] Jung, O-S., Kim, Y. J., Lee, Y-A., Park, J.K., Chae, H.K. (2000). Smart Molecular Helical Springs as Tunable Receptors. Journal of American Chemical Society, 122: 9921-9925.

[25] Susanta, K.M., Sachin, U.S., Radha, V.J., Parasuraman, S. (2002). Regio- and Chemoselective Catalytic Transfer Hydrogenation of Aromatic Nitro and Carbonyl as Well as Reductive Cleavage of Azo Compounds over Novel Mesoporous NiMCM-41 Molecular Sieves. Organic Letters, 4: 4297-4300.

[26] Desai, D.G., Swami, S.S., Dabhade, S.K., Ghagare M.G. (2001). Fes- $\mathrm{NH}_{4} \mathrm{Cl}-\mathrm{CH}_{3} \mathrm{OH}$ $\mathrm{H}_{2} \mathrm{O}$ : An Efficient and Inexpensive System for Reduction of Nitroarenes to Anilines. Synthetic Communications, 31: 1249-1251.

[27] Boris, L.T.L., William, C.H., Kaoru, I., Olga F., Alan, W.D. (2013). A Preliminary Assessment of the Interactions Between the Capping Agents of Silver Nanoparticles and Environmental Organics. Colloids and Surfaces A: Physicochem. Eng. Aspects, 435: 22-27.

[28] Subhra, J., Sujit, K.G., Sudip, N., Surojit, P., Snigdhamayee, P., Sudipa, P., Soumen, B., Takeshi, E., Tarasankar, P. (2006). Synthesis of Silver Nanoshell-Coated Cationic Polystyrene Beads: A Solid Phase Catalyst for the Reduction Of 4-Nitropheno. Applied Catalysis A: General, 313: 41-48. 